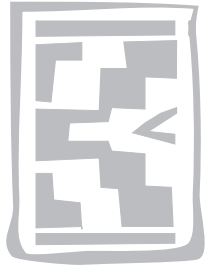

\title{
Acute and long-term effects of exposure to sodium monofluoroacetate (1080) in sheep
}

\author{
S.R. GOONERATNE ${ }^{1,2}$, C.T. EASON², 3 , L. MILNE², D.G. ARTHUR ${ }^{4}$, C. COOK $^{5}$ and \\ M. WICKSTROM 2,6
}

\begin{abstract}
S.R. GOONERATNE, C.T. EASON, L. MILNE, D.G. ARTHUR, C. COOK \& M. WICKSTROM. 2008. Acute and long-term effects of exposure to sodium monofluoroacetate (1080) in sheep. Onderstepoort Journal of Veterinary Research, 75:127-139

Acute and long-term effects of a single, relatively high oral dose $(0.25$ and $0.30 \mathrm{mg} / \mathrm{kg})$ of sodium monofluoroacetate (1080) on the survival and productivity of sheep were evaluated to establish a better understanding of 1080 poisoning and identify more specific changes diagnostic of toxicosis.

In survivors, clinical signs of acute 1080 toxicosis such as salivation and lethargy were generally very mild. Fasted animals were more prone to 1080 toxicity. In animals that died, more severe signs, including tachypnoea, dyspnoea, and tremors occurred for 15-20 min prior to death. 1080 concentrations were highest in the blood > heart > skeletal muscle > liver. 1080 could not be detected in any of these organs of the animals that survived. Serum citrate concentrations were elevated for 4 days after dosing. No clinical or biochemical abnormalities were found in any animal after 4 days. Histopathological lesions were most marked in the heart and lung with inflammation, necrosis, and scattered foci of fibrous tissue in the myocardium, pulmonary oedema and inflammation of the lung. No adverse longterm effects on general health or reproductive performance were observed in any sheep that survived the first 4 days following exposure to 1080 .

The most reliable diagnostic indicators of 1080 exposure in sheep were measurement of its residues in blood, skeletal muscle and ruminal contents, increased serum citrate concentration; elevated heart rate, and characteristic electrocardiograph changes (up to 4 days after exposure). Death from 1080 is most likely to occur within $96 \mathrm{~h}$, and animals that survived this period appeared normal.
\end{abstract}

Keywords: Cardiotoxicity, sheep, sodium monofluoroacetate, vertebrate pest control

1 Cell Biology Group, Agriculture and Life Sciences Division, P.O. Box 84, Lincoln University, Lincoln 7647, Canterbury, New Zealand

2 CENTOX (Centre for Environmental Toxicology), Landcare Research, P.O. Box 69, Lincoln 7647, New Zealand

3 Bio-Protection and Ecology Division, Lincoln University/Te Whare Wanaka o Aoraki, P.O. Box 84, Lincoln University, Lincoln 7608, Canterbury, New Zealand

4 LabWorks Animal Health Ltd, P.O. Box 113, Lincoln University, New Zealand

5 Hort+Research, Ruakura Research Centre, Hamilton, New Zealand

6 Western College of Veterinary Medicine, University of Saskatchewan, Saskatoon, SK, Canada

Accepted for publication 14 April 2008-Editor

\section{INTRODUCTION}

Sodium monofluoroacetate (1080) is both a natural plant toxin and a vertebrate pesticide. In New Zealand, it is widely used to control numbers of Australian brushtail possums (Trichosurus vulpecula), the wildlife maintenance host of the tuberculosis bacterium, Mycobacterium bovis. 1080 has many advantages compared with alternative vertebrate pesticides, including low cost, a high degree of efficacy and relative humaneness in the target species, and lack of environmental persistence and potential to bioaccumulate (Eason 1997). As a result, 1080 is likely to continue to play an integral part in the management of possum numbers in New Zealand. 
In spite of stringent operational procedures for the use of 1080 in New Zealand, livestock are occasionally inadvertently exposed to toxic baits during possum control operations. Teratogenicity studies in rats showed that when female rats were exposed to relatively high doses $(0.33$ and $0.75 \mathrm{mg} / \mathrm{kg})$ in the initial third of their gestation which includes the organogenesis period, mild skeletal effects occur in foetuses (Eason, Wickstrom, Turck \& Wright 1999). Accidental 1080 poisoning has highlighted the need for improved methods of early diagnosis of exposure, and a better understanding of both acute and chronic effects of the toxin. In particular, despite anecdotal reports of decreased reproductive performance and a higher incidence of infectious diseases, there are apparently no reports of controlled studies to evaluate the potential long-term effects of a single sublethal exposure on health and productivity of livestock.

Clinical signs of acute 1080 poisoning include nausea and vomiting (in species that vomit), cyanosis, depression, tremors, ataxia and convulsions within $24 \mathrm{~h}$ post exposure. Marked species variation has been reported in the literature with mild signs of toxicosis in herbivores, such as sheep, exhibiting predominantly lethargy, whereas clinical signs in carnivores include repeated vomiting and convulsions (Egekeze \& Oehme 1979). Death is often attributed to ventricular fibrillation and/or respiratory failure (Egekeze \& Oehme 1979). Elevations in blood 1080 (Eason, Gooneratne, Fitzgerald, Wright \& Frampton 1994) and serum citrate (Mead, Moulden \& Twigg 1985) concentration are the most consistent antemortem indicators of recent exposure (i.e. within 14 days). Other reported biochemical changes associated with 1080 toxicosis include hypocalcaemia (Roy, Taitelman \& Burstein 1980) and lactic acidosis (Buffa, Guarrievo-Bobyleva \& Costa-Tlozzo 1973). Mucous membrane cyanosis and petechiae in the epicardium, endocardium and the mucous membranes of the epiglottis and trachea are common macroscopic post-mortem observations (Egekeze \& Oehme 1979). Histopathological changes have been reported in the heart of sheep (Whittem \& Murray 1963; Schultz, Coetzer, Kellerman \& Naude 1982) and guinea pigs (Peters 1963), and in the testes (Smith, Gardner, Yuile, De Lopez \& Hall 1977; Sullivan, Smith \& Garman. 1979; Twigg, King \& Bradley 1988; Eason \& Turck 2002), brain (Koenig 1969) and kidneys (McDowell 1972a, b) of rats. Previously reported 1080-induced cardiac damage in sheep has been based on multiple or unspecified exposures to the toxin, and has been described as degeneration and necrosis of individual or small groups of myofibres (Schultz et al. 1982), and acute, multifocal myocardial injury (Whittem \& Murray 1963).

The aims of this study were to identify specific 1080 induced histopathological changes and/or clinical chemistry endpoints that may improve the diagnosis of acute 1080 poisoning in livestock, and to determine if any long-term adverse effects of poisoning on the health, productivity, reproductive performance and pathological lesions occur in sheep that survive a near-lethal exposure to the toxin. Because cardiac damage and a number of clinical signs suggestive of central nervous system involvement including effects on glial cell uptake and neurotransmitter regulation (Hassel, Bachelard, Jones, Fonnum \& Sonnewald 1997) has been previously reported in sheep following 1080 poisoning, particular attention was paid to the brain and heart.

As livestock poisoning incidences cannot unfortunately be completely avoided, it is important that the consequences of short- and long-term exposure are understood. Two separate studies were conducted. In Experiment 1, the acute effects of a single, relatively high oral dose of 1080 were evaluated in an attempt to identify more specific and sensitive diagnostic endpoints of toxicosis. Experiment 2 evaluated the potential adverse effects of a single, nearlethal 1080 exposure of fasted and non-fasted sheep on the long-term health of these animals. The Landcare Research Animal Ethics Committee reviewed and approved these experiments.

\section{MATERIALS AND METHODS}

\section{Experimental animals}

Thirteen young Merino cross (half-bred) males and 71 ewes (approximately 1 year old) were purchased from a single stud farm. Standard farming practices, including drenching and vitamin supplementation, were carried out before and after exposure to 1080 . All animals were drenched with selenium (Se) 3 weeks prior to the start of the experiment in November 1994, and adequate Se status was confirmed by analysis (Board \& Peter 1976) of a subsample of five ewes within a week of dosing (blood Se concentration $=29-39 \mathrm{IU} / \ell$ ). Two experiments were conducted and details are given below. The mean live mass of 13 male and 13 female sheep at the commencement of Experiment 1 were $54.5 \mathrm{~kg}$ (range $=46.2-63.5 \mathrm{~kg}$ ), and $36.4 \mathrm{~kg}$ (range $=29.0-$ $44.5 \mathrm{~kg}$ ), respectively. The mean live mass of 58 female sheep in Experiment 2 was $48.0 \mathrm{~kg}$ (range = 
42.0-60.2 kg). All experiments were conducted under veterinary supervision with experienced animal technicians to ensure suffering was minimized. Death was used as an endpoint so that the time course of events to mortality or recovery following 1080 exposure could be better understood.

\section{Experiment 1: Acute effects of 1080}

\section{Animals and dosing regimen}

Twenty-six sheep were housed in individual elevated cages and maintained on chaffed lucerne hay and sheep pellets ad libitum for 7 days before, and 7 days after dosing. Animals were not fasted prior to dosing. The experiment was conducted in two phases where test animals in Phase 1 received a higher dose of 1080 (0.30 mg/kg live mass) than animals in Phase $2(0.25 \mathrm{mg} / \mathrm{kg}$ ). Eight sheep (four females and four males) were dosed with $2 \mathrm{~m} / \mathrm{kg}$ water (controls). Sodium monofluoroacetate was dissolved in water and administered to 18 sheep (six females and six males received the higher dose and three animals of each sex received the lower dose) by gastric intubation at a volume of $2 \mathrm{ml} / \mathrm{kg}$. Animals that survived exposure to 1080 were returned to pasture after 7 days, and allowed to graze until euthanased on Day 14.

\section{Clinical signs of acute 1080 toxicosis}

Sheep were visually examined for clinical signs of 1080 intoxication every $2 \mathrm{~h}$ for the first $72 \mathrm{~h}$ after dosing, at least twice a day on Days 4-7, then at least once a day until humanely killed on Day 14. Heart function was monitored using an electrocardiograph (Cardisuny 501A), and up to ten electrocardiograms (ECG) were recorded per sheep, both before and daily during the first week after exposure.

\section{Toxicokinetics, haematology, and clinical biochemistry}

Blood samples were collected by jugular venepuncture $24 \mathrm{~h}$ before dosing, immediately prior to dosing, at 2, 4, 8, and $24 \mathrm{~h}$ after dosing, and on Days 3, 5, 7 , and 14 post-dosing. Serum and plasma were stored at $-20{ }^{\circ} \mathrm{C}$ until analysed. Results were subjected to repeated-measures statistical analyses.

Sera from three of the ewes dosed at $0.30 \mathrm{mg} 1080$ per $\mathrm{kg}$ that survived to Day 14 were analysed for 1080 residues using gas chromatography (Eason et al. 1994). Skeletal and cardiac muscle, kidney, and liver were collected from these sheep for 1080 residue analysis. Routine haematological analyses were conducted using a Cobas Minus Vet blood cell counter (Roche, Basel, Switzerland). Serum citrate concentration was measured with a commercial enzymatic assay kit (Boehringer Mannheim, Germany).

Automated analyses of creatine kinase (CK), aspartate aminotransferase (AST), gamma glutamyltransferase (GGT), glutamate dehydrogenase (GLDH), were conducted at $21^{\circ} \mathrm{C}$, and glucose, phosphate, creatinine, urea and serum calcium at room temperature using a Hitachi 704 Analyser (Boehringer Mannheim, Germany). Ionised calcium was measured by an ion selective electrode method and total protein by refractometry.

\section{Pathology}

Complete post-mortem examinations were usually carried out within $5 \mathrm{~h}$ of death in animals that died of 1080 toxicity. Control animals and the 1080 survivors were euthanased on Day 14 by captive bolt followed by exsanguinations and subjected to immediate post-mortem examination. Post-mortem examinations of 1080-dosed animals that survived to 14 days, and the histopathology of their tissues (see below) were conducted 'blind'. Tissue samples (heart, lung, kidney, liver, brain, skeletal muscle, abomasum, rumen, duodenum, ovaries or testes, oesophagus, trachea, spleen, thymus, thyroid glands, bone marrow, adrenal glands and pancreas) were fixed in 10\% neutral buffered formalin, processed in paraffin wax, sectioned and stained using haematoxylin and eosin (H\&E) for histopathology.

\section{Experiment 2: Long-term effects of a near-lethal dose of 1080}

\section{Animals and dosing regimen}

This experiment was also conducted in two phases. In Phase 1, six non-fasted ewes were dosed with 1080 at $0.20 \mathrm{mg} / \mathrm{kg}$, and the control group of six ewes received water only. In Phase 2, six non-fasted ewes were dosed with 1080 at $0.25 \mathrm{mg} / \mathrm{kg}$, and a second treatment group of 22 ewes were fasted for $18 \mathrm{~h}$ before receiving the same dose of 1080 . The control group for the Phase 2 of this experiment consisted of 18 ewes. All of the sheep were returned to pasture immediately after dosing, and observed at least twice a day for the first 3 days, and daily from then onwards. Complete post-mortem examinations were conducted on 12 animals that died of acute poisoning and one control, and tissue samples taken for histopathology, as in Experiment 1. 
Effects of 1080 on general health and reproductive performance

A total of 44 animals, 21 out of 34 treated animals that survived acute poisoning and 23 out of 24 (one died of unknown causes) control ewes were managed as one flock. They were weighed monthly, and maintained under normal farming practices. They were mated in March to April 1995, and maintained over the winter in a mixed flock of 500-600 sheep on a rotational grazing management system at a density of approximately 15 sheep per ha. A month before lambing, ewes in this trial were separated from the flock, weighed, shorn and their fleece weighed. Mean fleece mass from 1080 treated versus control ewes was compared by student's $t$-test \pm standard error. They were monitored closely from the onset of lambing until the lambs were weaned in December 1995. The general and reproductive health of the exposed animals were assessed by comparing their live mass, and the incidence of pregnancy-related (e.g. pregnancy toxaemia) and post-partum (e.g. agalactia) metabolic and infectious diseases with those of the controls. Lambing percentage and survival rate were recorded at birth, and body mass of lambs were determined 8 weeks after the first lamb was born. Live mass of ewes (Fig. 7) was compared by repeat measures analysis of variance, with the initial pre-1080 treatment live mass as co-variant.

In Year 2, all ewes were returned to the flock and managed and monitored as in the previous year, including mating in March to April 1996. Ewes and lambs were maintained at pasture until the lambs were born and then disposed of.

\section{Haematology and clinical biochemistry}

A subset of the control and 1080-exposed ewes (ten per group) were humanely killed for post-mortem and histopathological examination in January 1997. Blood samples were collected by jugular venepuncture from these ewes just prior to euthanasia for measurement of complete blood counts, blood glucose, serum concentrations of citrate, calcium, phosphorus, urea nitrogen and creatinine, and CK, AST, GGT and GLDH activities, as described for Experiment 1.

\section{Pathology}

At post-mortem, tissue samples of heart, lung, kidney, liver, brain, skeletal muscle, rumen, abomasum, duodenum and ovaries were collected for histopathology. A transverse section was made of each heart midway between the apex and atrioventricular junction in order to obtain representative samples from the left and right ventricles and interventricular septae. Tissues were fixed in 10\% neutral buffered formalin, embedded in paraffin wax, sectioned and stained using H\&E for histopathology. Von Kossa stain was used to identify calcified lesions in the heart.

Brains from three 1080-exposed ewes were cut saggitally in $20 \mu \mathrm{m}$ thick sections on a freezing microtome and mounted onto gelatine-coated slides. Brains from three breed- and age-matched, nonexposed ewes were used as controls. These sections were alternatively stained, using a Fluoro-Jade histochemical technique for neuronal degeneration (Schumed, Albertson \& Slikker 1997) and for immunohistochemical localization of nitric oxide synthase (NOS)-containing neurons, as described by Gai \& Blessing (1996). They were examined using light microscopy with epifluorescent technique for signs of toxin-induced damage.

\section{RESULTS}

\section{Acute effects of 1080}

\section{Mortality}

In Experiment 1, five out of 12 sheep exposed to 1080 at $0.30 \mathrm{mg} / \mathrm{kg}$ died between 22 and $96 \mathrm{~h}$ after dosing. Three of the six sheep exposed to the lower dose of $0.25 \mathrm{mg} / \mathrm{kg}$ died at $25-52 \mathrm{~h}$ (Table 1). The severity of clinical signs of toxicosis in one animal in the $0.25 \mathrm{mg} / \mathrm{kg}$ dose group was exacerbated by pre-existing pleurisy, which was diagnosed at post mortem.

In Experiment 2, none of the six ewes exposed to 1080 at $0.20 \mathrm{mg} / \mathrm{kg}$ died. Only one out of six nonfasted ewes given 1080 at $0.25 \mathrm{mg} / \mathrm{kg}$ died, $72 \mathrm{~h}$ after dosing, but 12 out of 22 ewes given the same dose after fasting for $18 \mathrm{~h}$ died at 28-96 $\mathrm{h}$ (Table 1). No further deaths occurred after $96 \mathrm{~h}$.

Clinical signs observed in the sheep that died in both Experiments 1 and 2 included excessive salivation, lethargy, tachypnoea, dyspnoea, tremors and muscle spasms, coma and terminal tonic convulsions. It was difficult to predict which individual 1080-exposed sheep were likely to die because in most of the animals the clinical signs were initially very mild, consisting mostly of salivation and/or lethargy and/or tachypnoea. It was not until the final 15-20 min of life when their clinical condition deteriorated rapidly, with increasing dyspnoea accom- 
TABLE 1 Mortality of sheep following exposure to sodium monofluoroacetate (1080)

\begin{tabular}{|c|c|c|c|}
\hline \multirow{2}{*}{$\begin{array}{l}1080 \text { dose } \\
(\mathrm{mg} / \mathrm{kg})\end{array}$} & \multicolumn{3}{|c|}{ Mortality } \\
\hline & Male & Female & Time to death (h) \\
\hline \multicolumn{4}{|l|}{ Experiment 1} \\
\hline $\begin{array}{l}0.00 \\
0.25 \\
0.30\end{array}$ & $\begin{array}{l}0 / 4 \\
2 / 3 \\
3 / 6\end{array}$ & $\begin{array}{l}0 / 4 \\
1 / 3 \\
2 / 6\end{array}$ & $\begin{array}{l}- \\
25,44,52 \\
22,24,43,50,89-96\end{array}$ \\
\hline \multicolumn{4}{|l|}{ Experiment 2} \\
\hline $\begin{array}{l}\text { Not dosed } \\
0.00 \\
0.20 \\
0.25 \\
0.25 \text { (fasted) }\end{array}$ & $\begin{array}{l}- \\
- \\
- \\
-\end{array}$ & $\begin{array}{c}0 / 18 \\
1 / 6^{\mathrm{a}} \\
0 / 6 \\
1 / 6 \\
12 / 22\end{array}$ & $\begin{array}{l}- \\
96 \\
- \\
72 \\
<20,<20,<20,<20,21,28,28,36,72,72,96,96\end{array}$ \\
\hline
\end{tabular}

a Death due to unknown cause

TABLE 2 Pulmonary oedema or myocardial lesions detected at post mortem or on histopathological examination, following exposure to sodium monofluoroacetate (1080)

\begin{tabular}{|c|c|c|c|c|c|}
\hline \multirow[b]{2}{*}{ Treatment group } & \multirow{2}{*}{$\begin{array}{l}\text { No. of sheep } \\
\text { examined }\end{array}$} & \multicolumn{2}{|c|}{ Pulmonary oedema } & \multicolumn{2}{|c|}{ Myocardial lesions $†$} \\
\hline & & $\begin{array}{l}\text { Post mortem } \\
\text { gross lesions }\end{array}$ & Histology & $\begin{array}{l}\text { Post mortem } \\
\text { gross lesions }\end{array}$ & Histology \\
\hline $\begin{array}{l}\text { Controls }^{a} \\
\text { Survivors }^{b}\end{array}$ & $\begin{array}{r}8 \\
10\end{array}$ & $\begin{array}{l}0 \\
0\end{array}$ & $\begin{array}{l}0 \\
1^{\mathrm{C}}\end{array}$ & $\begin{array}{l}0 \\
2\end{array}$ & $\begin{array}{l}0 \\
2\end{array}$ \\
\hline \multicolumn{6}{|l|}{ Acute deaths } \\
\hline $\begin{array}{l}\text { Experiment } 1 \\
\text { Experiment } 2\end{array}$ & $\begin{array}{r}8 \\
13^{d}\end{array}$ & $\begin{array}{r}6 \\
10\end{array}$ & $\begin{array}{r}8 \\
11\end{array}$ & $\begin{array}{l}2 \\
0\end{array}$ & $\begin{array}{l}4^{e} \\
6\end{array}$ \\
\hline
\end{tabular}

a Euthanased at 14 days (Experiment 1)

b Euthanased at 14 days (Experiment 1)

c Focal oedema

d This includes 12 of the 13 1080-dosed and one control sheep that died within $96 \mathrm{~h}$ of commencement of the experiment. One ewe from the $0.25 \mathrm{mg} 1080$ per $\mathrm{kg}$ in the fasted group was not subjected to post mortem examination due to autolysis

e One heart was not saved for histopathology

$\dagger$ mycocardial necrosis/mineralization

TABLE 3 Reproductive performance of ewes following exposure to sodium monofluoroacetate (1080)

\begin{tabular}{|l|l|l|l|l|}
\hline \multirow{2}{*}{} & \multicolumn{2}{l|}{ Control ewes } & \multicolumn{2}{l|}{ 1080-exposed ewes } \\
\cline { 2 - 5 } & 1995 & 1996 & 1995 & 1996 \\
\cline { 2 - 5 } No. of ewes bred (\%) & $23(100)$ & $23(100)$ & $21(100)$ & $20(95)$ \\
No. of lambs born (\%) & $39(162)$ & $40(174)$ & $32(152)$ & $33(165)$ \\
No. of lambs surviving (\%) & $25(104)$ & - ANA $^{\mathrm{b}}$ & $24(114)$ & - ANA $^{\mathrm{b}}$ \\
Mean birth mass $(\mathrm{kg})$ & $-\mathrm{NR}^{\mathrm{a}}$ & 4.6 & NR $^{\mathrm{a}}$ & 5.1 \\
Mean lamb live mass $(\mathrm{kg})^{\mathrm{c}}$ & 18.2 & - ANA $^{\mathrm{b}}$ & 21.4 & ANA $^{\mathrm{b}}$ \\
\hline
\end{tabular}

a -NR denotes 'not recorded'

b -ANA denotes 'animals not available'

c Lamb live mass was determined 8 weeks after the onset of lambing

panied by muscle spasms progressing to tonic seizures and coma. Only mild signs of toxicosis such as salivation and/or lethargy were apparent for the first $24 \mathrm{~h}$ after dosing in the ten animals that sur- vived 1080 exposure in Experiment 1. However, most of the survivors exhibited tremors and irregular respiration when blood samples and/or ECGs were taken. All ten survivors from the fasted group in 
Experiment 2 demonstrated signs of mild toxicosis, namely salivation and tachypnoea and/or lethargy. As in Experiment 1, these signs were exacerbated when animals were stressed such as or during handling for blood collection or ECG recordings. The non-fasted survivors exhibited fewer clinical signs.

Toxin-induced ECG changes were first observed at $2.5 \mathrm{~h}$ after 1080 exposure. These changes were most pronounced by about $4.5 \mathrm{~h}$ after exposure and were characterized by S-T segment elevation and a 300\% increase in T-wave amplitude. Average heart rate also increased by up to $35 \%$ within $4.5 \mathrm{~h}$ of 1080 exposure. All indicators of cardiotoxicity were most marked in sheep that died of 1080 toxicosis. In the animals that survived, heart rate and ECG parameters returned to normal 3-4 days after dosing.

\section{Toxicokinetics, haematology, and clinical} biochemistry (Experiment 1)

Serum 1080 concentrations in ewes $(n=3)$ dosed at $0.30 \mathrm{mg} / \mathrm{kg}$ peaked at $0.32-0.35 \mu \mathrm{g} / \mathrm{ml}$ between 2 and $4 \mathrm{~h}$ after dosing. Serum concentrations declined to $0.10 \mu \mathrm{g} / \mathrm{ml}$ by $24 \mathrm{~h}$, and were undetectable 3 days after dosing (Fig. 1).

No 1080 was detected in the skeletal muscle, kidney and liver of three animals that survived to Day 14 after 1080 treatment (limit of detection = $0.0015 \mu \mathrm{g} / \mathrm{g})$. However, the 1080 concentrations in the heart of animals that died 22-25 h after 1080 exposure $(n=3)$ were $0.061-0.075 \mu \mathrm{g} / \mathrm{g}$, slightly higher than in the skeletal muscle $(0.058-0.072 \mu \mathrm{g} / \mathrm{g})$ and the liver $(0.047-0.051 \mu \mathrm{g} / \mathrm{g})$. The skeletal muscle 1080 concentration were lower and varied between $0.023-0.031 \mu \mathrm{g} / \mathrm{g}$ in animals that died $43-52 \mathrm{~h}$ after dosing $(n=4)$ but undetectable in the heart and liver. Concentrations of 1080 were $0.15-0.27 \mu \mathrm{g} / \mathrm{g}$ in the ruminal contents of sheep that died within $24 \mathrm{~h}$ of dosing $(n=2)$.

No changes in haematological parameters were observed in 1080-exposed sheep relative to control animals or pre-dose values. Serum citrate concentrations in sheep (six males and six females) dosed with 1080 at $0.30 \mathrm{mg} / \mathrm{kg}$ were significantly greater $(P<0.05)$ than in the control sheep (four males and four females) at 4,8 and $24 \mathrm{~h}$ of exposure with the peak level reached at $24 \mathrm{~h}$ (Fig. 2). Serum citrate concentrations returned to normal by $72-96 \mathrm{~h}$ after exposure to 1080 . No difference in serum citrate concentration was observed between 1080-exposed animals that died (three males and two females) and those that survived to Day 14 .

Blood glucose and urea nitrogen concentrations and AST activity were elevated in 1080-exposed sheep, both in animals that died (three males and five females) and those that survived 14 days (six males and four females) compared to controls (four males and four females) (Fig. 3), but only glucose concentrations exceeded normal laboratory reference values for sheep. No other clinical chemistry parameters were abnormal.

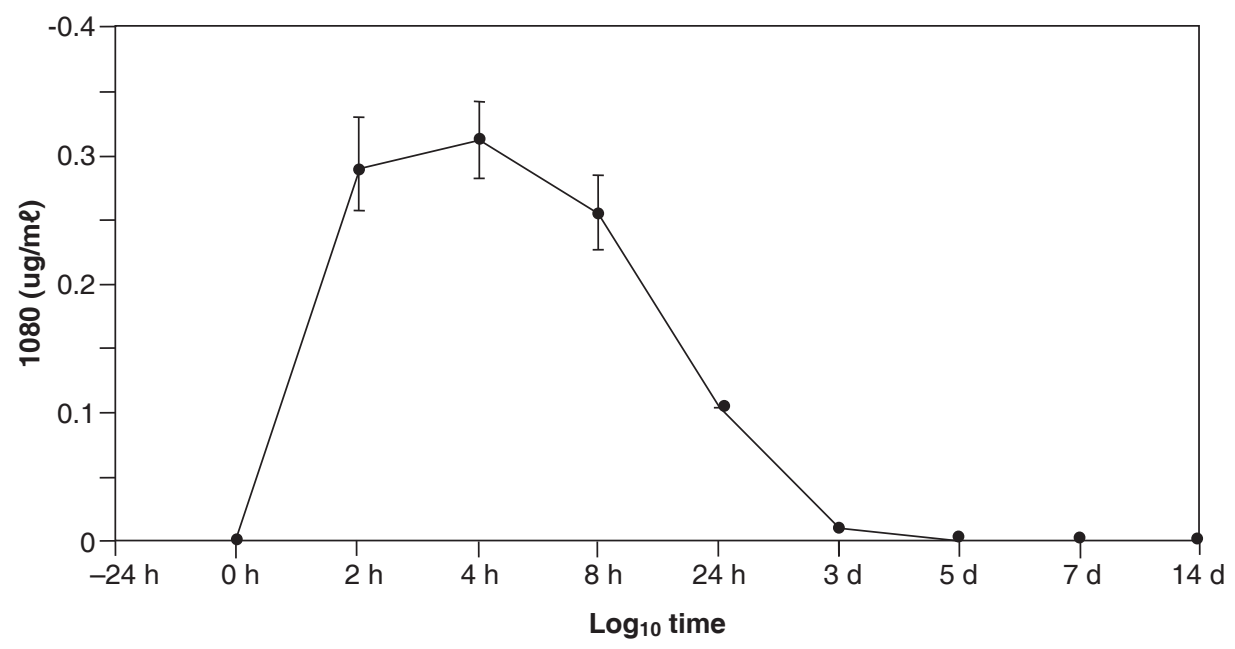

FIG. 1 Mean ( \pm SEM) serum sodium monofluoroacetate $(1080)$ concentration $(\mu \mathrm{g} / \mathrm{ml})$ in ewes $(n$ = 3) dosed with $0.30 \mathrm{mg} 1080$ per $\mathrm{kg}$ from $-24 \mathrm{~h}$ to Day 14 after exposure (Experiment 1)

No errors are given where the value was below the limit of detection or on one occasion $(24 \mathrm{~h})$ when all samples contained the same concentration of 1080 


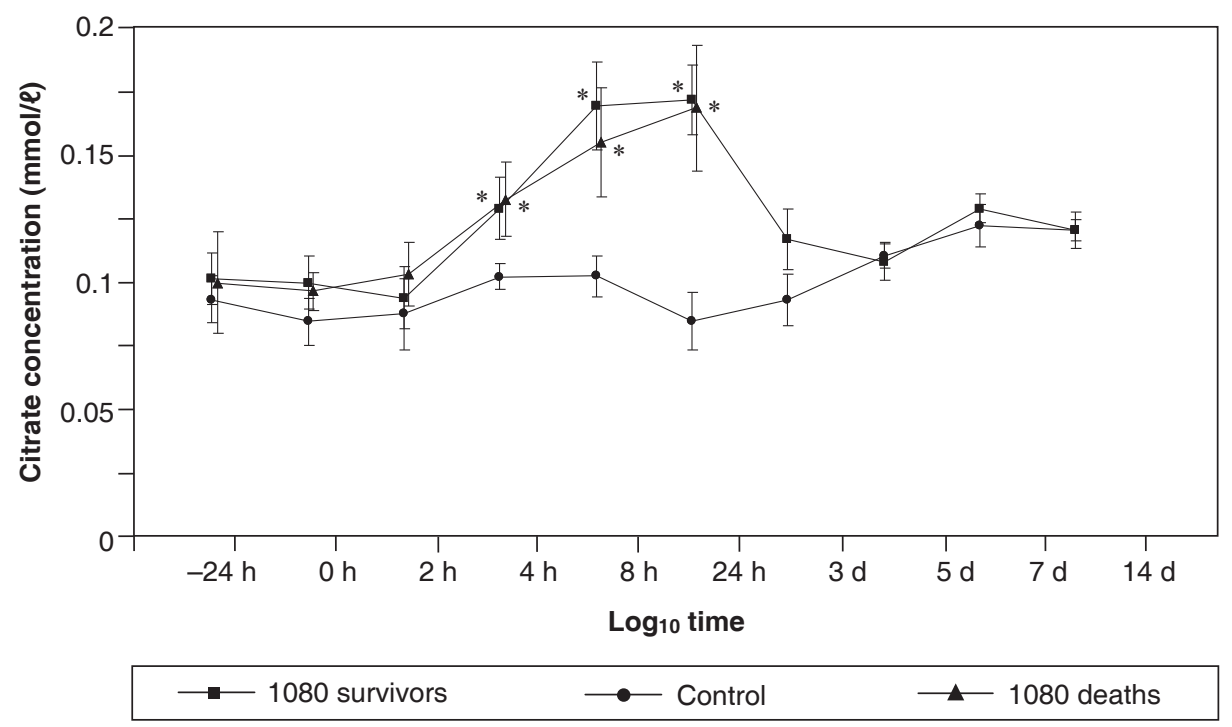

FIG. 2 Mean ( \pm SEM) serum citrate concentration $(\mathrm{mmol} / \ell)$ in sheep that survived $(\mathbf{a} ; n=7)$, or died $(\wedge ; n=5)$, following dosing with $0.30 \mathrm{mg}$ sodium monofluoroacetate (1080) per $\mathrm{kg}$, and in control sheep $(\bullet ; n=8)$, from $-24 \mathrm{~h}$ to Day 14 after exposure (Experiment 1 ). The asterisks $\left(^{*}\right)$ denote a significant difference $(P<0.05)$ from the controls at that time period

\section{Pathology (Experiments 1 and 2)}

Gross or microscopic lesions that could be attributed to 1080 exposure were observed only in the lungs and/or heart in both Experiments 1 and 2, and were identified most consistently in sheep that died within 4 days of 1080 exposure (Table 2). The heart was the only organ in which toxin-induced abnormalities were detected in sheep euthanased 14 days after exposure.

Severe, diffuse pulmonary oedema affecting all lung lobes was the most common post-mortem finding in these animals. The lungs were wet and heavy and clear fluid drained from cut surfaces. The trachea was usually filled with a frothy fluid. Histologically, alveolar spaces were filled with proteinaceous fluid and small numbers of macrophages and inflammatory cells were present in alveolar septa (Fig. 4). Some animals in both the control and treatment groups also had lung lesions attributable to parasites (Muelleria spp.) or enzootic pneumonia. These were focal or locally extensive lesions and were easily distinguishable from the diffuse congestion and oedema (Fig. 5) induced by 1080.

Significant gross cardiac lesions were observed only in four of the 1080-exposed sheep in Experiment 1 and none in Experiment 2. These lesions were characterized by single focal areas of mineralization, approximately $10 \mathrm{~mm}$ in diameter, within the myocardium of the interventricular septum, papillary muscle or left ventricular free wall. The lesions were visible from either epicardial or endocardial surfaces. Endocardial and/or epicardial haemorrhages were frequently observed in both the treated and control sheep and were considered to be an agonal change. Three standard sections of cardiac muscle were examined histologically from all sheep in Experiment 1 $(n=26)$, and from 13 of the 14 sheep in Experiment 2 that died within 4 days of 1080 exposure (Table 2). Significant histologic lesions were present in the heart of 12 sheep. These lesions were characterized by multifocal to locally extensive areas of necrosis and mineralization of cardiac myofibres, sometimes associated with infiltration of macrophages and lymphocytes (Fig. 6).

\section{Long-term effects of a near-lethal dose of 1080 (Experiment 2)}

\section{General health and reproductive performance of surviving ewes}

Twenty-three of 24 control ewes and all 21 ewes that survived exposure to 1080 remained until termination of Experiment 2 in January 1997. No adverse effects on general health or condition were observed in any of the animals during the first or second year after dosing in the 21 ewes surviving 1080 exposure. There was no apparent increase in the incidence of infectious or metabolic diseases compared with controls and no deaths among the survivors. One control ewe died of a suspected clostridial infection after the second lambing. No differ- 

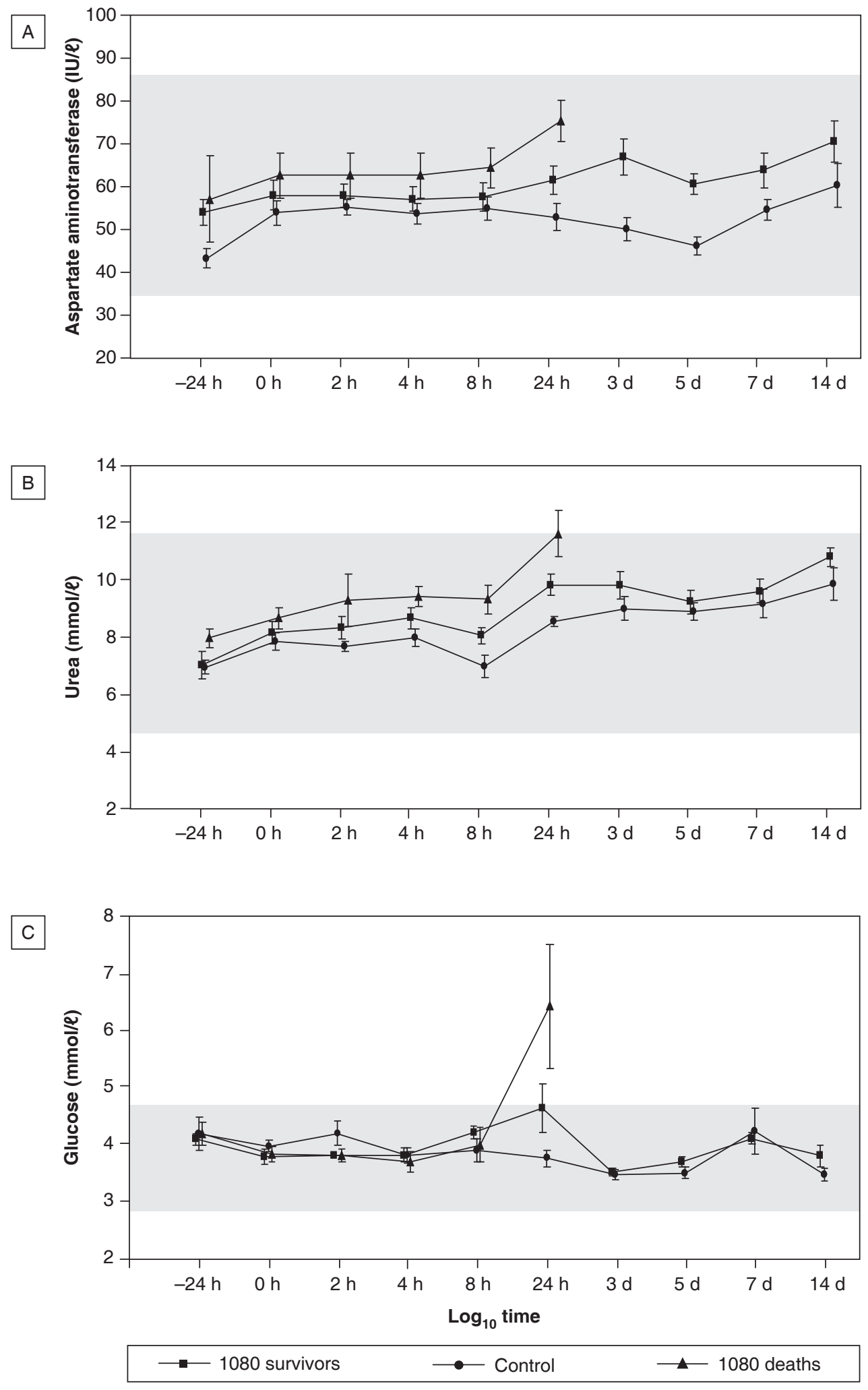

FIG. 3 Effect of sodium monofluoroacetate (1080) administration (at $\log _{10}$ time 0 ) on (A) plasma aspartate aminotransferase activity, (B) serum urea, and (C) blood glucose concentrations $( \pm$ SEM) in sheep which survived $(\boldsymbol{\square} ; n=7)$, or died $(\wedge ; n=5)$, following dosing with $0.30 \mathrm{mg}$ sodium monofluoroacetate (1080) per $\mathrm{kg}$, and in control sheep $(\bullet ; n=8)$, from $-24 \mathrm{~h}$ to Day 14 after exposure (Experiment 1 ). The shaded areas denote the normal range 

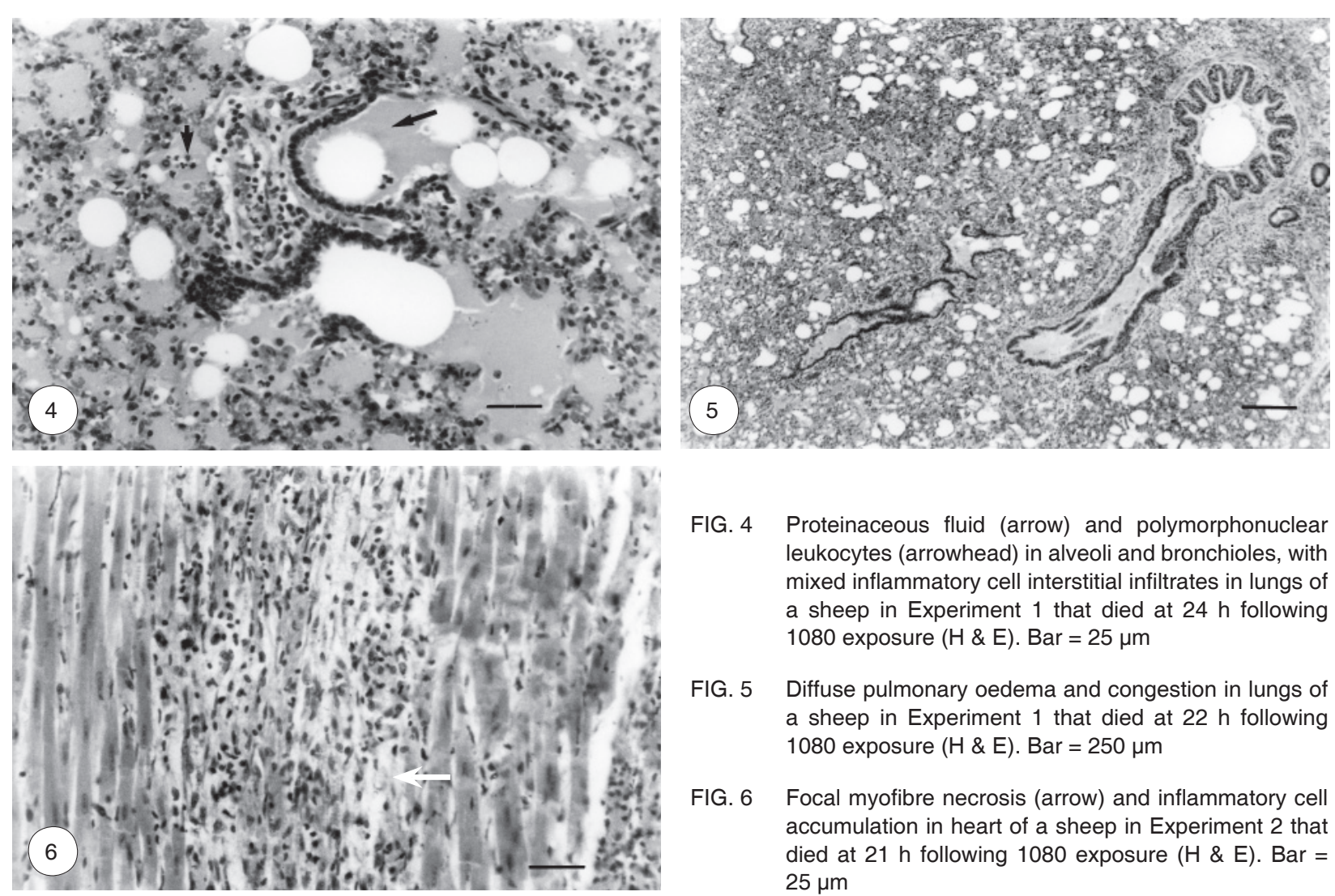

FIG. 4 Proteinaceous fluid (arrow) and polymorphonuclear leukocytes (arrowhead) in alveoli and bronchioles, with mixed inflammatory cell interstitial infiltrates in lungs of a sheep in Experiment 1 that died at $24 \mathrm{~h}$ following 1080 exposure $(H \& E)$. Bar $=25 \mu \mathrm{m}$

FIG. 5 Diffuse pulmonary oedema and congestion in lungs of a sheep in Experiment 1 that died at $22 \mathrm{~h}$ following 1080 exposure $(H \& E)$. Bar $=250 \mu \mathrm{m}$

FIG. 6 Focal myofibre necrosis (arrow) and inflammatory cell accumulation in heart of a sheep in Experiment 2 that died at $21 \mathrm{~h}$ following 1080 exposure $(\mathrm{H} \& \mathrm{E})$. Bar = $25 \mu \mathrm{m}$

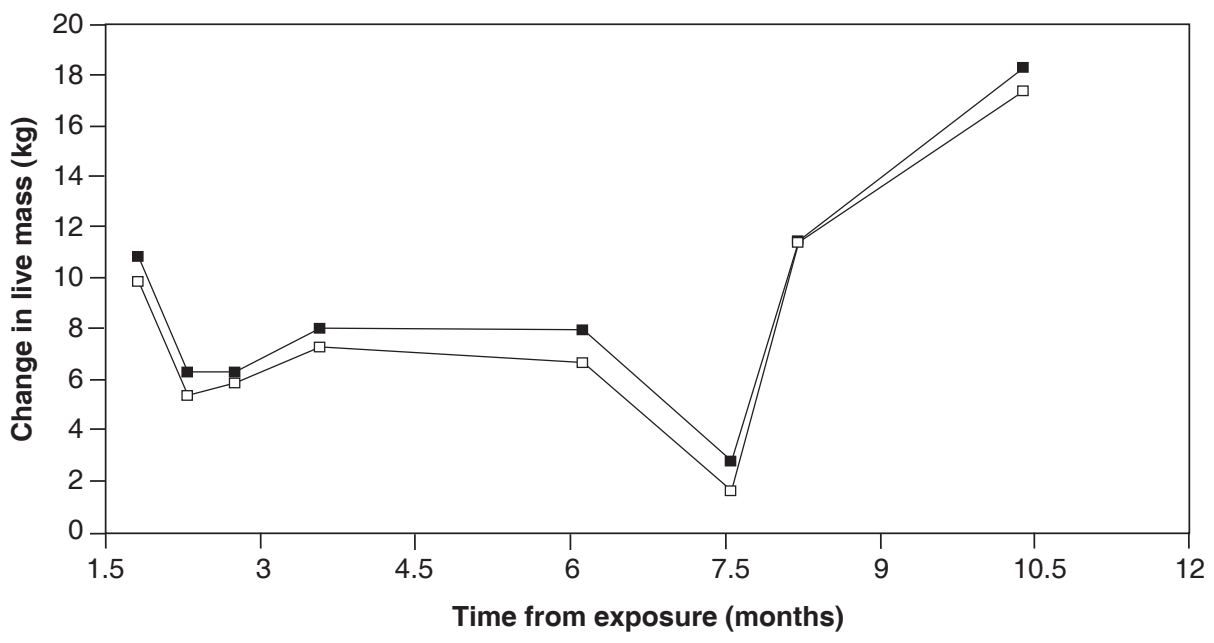

$\longrightarrow 1080$ ewes $\longrightarrow$ Control ewes

FIG. 7 Change in live mass of 21 ewes that survived exposure to sodium monofluoroacetate (1080) ( $\square$ ) compared with that of 23 control ewes $(\square)$ during the first year following dosing with 1080 (Experiment 2)

ence in mean live mass was detected between control animals and 1080-exposed ewes during the first year after dosing (Fig. 7). The seasonal fluctuations in body mass observed in both groups reflected changes in pasture availability. Average fleece mass of 1080-exposed ewes in the first $(5.63 \pm 0.2 \mathrm{~kg})$ and second $(4.5 \pm 0.1 \mathrm{~kg})$ years after dosing was not significantly different from that of the control sheep $(5.54 \pm 0.1 \mathrm{~kg} ; P=0.67$ and $4.37 \pm 0.1 \mathrm{~kg} ; P=0.37$, respectively). 
Exposure to a near-lethal dose of 1080 also had no adverse effect on the reproductive performance of ewes in the 2 years following exposure. In 1995 (Year 1), there was no difference in lambing percentage $(P=0.54)$, lamb survival $(P=0.55)$, or mean lamb live mass $(P=0.58) 8$ weeks after the onset of lambing between 1080-exposed ewes and the control group. In Year 2, there were again no differences in lambing percentage $(P=0.07)$, lamb survival $(P=$ 0.5 ) and mean lamb birth mass $(P=0.07)$ in 1080-exposed versus control groups (Table 3 ).

\section{Haematology and clinical biochemistry}

Results of analysis of blood and serum samples revealed no exposure-related changes in haematological or clinical biochemical parameters, indicating no chronic effects of 1080 on general health or organ function.

\section{Pathology}

There were no grossly visible pathological lesions in 1080-exposed ewes $(n=10)$ euthanased 2 years after dosing. Histopathological lesions were mostly restricted to the heart. Cardiac lesions were characterized by scattered foci of fibrous tissue in the myocardium. Non-specific brain lesions such as mild neuronal degeneration in the striatum, hippocampus and nucleus tractus solitarius were found in one 1080 exposed and one control sheep.

\section{DISCUSSION}

\section{Acute effects of 1080}

All deaths observed in sheep given a single oral dose of 1080 at $0.25-0.30 \mathrm{mg} / \mathrm{kg}$ occurred within 4 days of exposure. The high mortality rate in the fasted sheep was probably due to better absorption of 1080 from the gut. Animals that survived acute toxicosis appeared to recover completely, with no measurable clinical indicators of exposure apparent by Day 14. The most reliable diagnostic indicators of 1080 exposure in sheep were measurement of 1080 residues in blood, skeletal muscle and/or ruminal contents, increased serum citrate concentration, elevated heart rate and characteristic ECG changes, including S-T segment elevation and a marked increase in T-wave amplitude. These results are consistent with an earlier study in sheep, in which only traces of the toxin were detectable in blood and muscle after $96 \mathrm{~h}$ (Eason et al. 1994). The 1080 residue results confirm our previous suggestions that a withholding period of 5 days should be adequate to ensure residues are negligible from animals suspected to have been exposed to 1080 . In the surviving animals, all the parameters measured returned to normal, pre-dose baseline values within 3-4 days, thus were useful for only a limited time after exposure and only for early toxicokinetic evaluations in sheep (Eason et al. 1994). The concentration of 1080 in rumen contents as measured in two animals in this study have been shown to be reliable for diagnostic purposes (Rammell 1994).

The ECG changes observed in these ewes are suggestive of cardiac ischaemia. Similar ECG changes have been reported in cases of 1080 toxicosis in humans (Chi, Chen, Chan, Wu \& Huang 1996), but not in dogs (Matsubara, Kamiya \& Imai 1980). Species variation in target organ sensitivity may be due to differences in biochemical responses to the toxin. For example, in sheep exposed to a lethal or sublethal dose of fluoroacetate, the increase in tissue citrate concentration was more pronounced in the heart than in other organs (Annison, Hill, Lindsay \& Peters 1960; Schultz et al. 1982). Guinea pigs and rabbits also showed increased cardiac citrate concentrations and were sensitive to 1080-induced myocardial damage (Gooneratne, Eason, Dickson, Fitzgerald, Wright \& Wallace 1994). Rats demonstrated short-lived elevations of citrate concentration in the heart and a mixture of both cardiac and central nervous system signs when exposed to 1080 (Eason \& Turck 2002). In contrast, central nervous system signs predominate in dogs and elevation of heart citrate concentration is minimal (Bowsakowski \& Levin 1986). In addition, although the sample size was small $(n=12)$, the lack of correlation between serum citrate concentrations and probability of death or survival indicated that, whilst elevated citrate is a biomarker of exposure, the magnitude of serum citrate elevation was not a useful prognostic indicator in sheep.

Gross and microscopic pathology of the lungs and, to a lesser extent, cardiac changes were useful shortterm diagnostic indicators in sheep dying from 1080 poisoning. Cardiac damage was observed in 10 of the 21 sheep that died following exposure to 1080 . The pulmonary and cardiac lesions observed are not specific for 1080 poisoning in sheep and, therefore, when establishing a diagnosis, have to be considered together with the history of exposure, clinical signs of toxicosis and analysis of 1080 residues in tissue. Some cardiac damage may have been missed, since only four sections from each heart were examined, and the gross lesions were focal in distribution. Alternatively, the full expression of 1080- 
induced cardiac lesions in sheep may require multiple sublethal exposures. It may be relevant to note that the cardiotoxic effects of multiple doses of fluorouracil, a human chemotherapeutic agent, have been attributed to the metabolism of this drug to fluoroacetate (Lemaire, Arrelano, Malet-Martino, Martino \& De Foni 1994). Multifocal interstitial infiltrates of mononuclear cells, particularly lymphocytes, in the absence of necrosis or mineralization have been reported in the myocardium in association with 1080 exposure in sheep (Schultz et al. 1982). In the present study these lesions were observed in both treated and control sheep. Their significance in sheep poisoned with 1080 is therefore questionable. The presence of sarcocysts (Sarcocystis ovicanis) in myofibres of many of these sheep may have been responsible for the mononuclear infiltration, since these parasites are known to occasionally induce inflammatory responses in otherwise normal tissue (Jones, Hunt \& King 1997).

In this study, pulmonary changes were a more consistent finding than the cardiac lesions. Pulmonary oedema observed in these sheep may have been secondary to the cardiotoxic effects of 1080 . Most large animals that are necropsied a few hours after death have froth in the trachea. However, a direct effect of the toxin on the lungs cannot be ruled out. Pulmonary lesions, including oedema, have been previously reported in rats poisoned with fluoroacetate (Gardner, Nguyen \& White 1994). These researchers noted that the type of damage induced by fluoroacetate appeared to be similar to that produced in hyperoxia. The mechanism in either case may have been inhibition of aconitase activity in the lungs (Gardner et al. 1994).

\section{Long-term effects of a near-lethal dose of 1080}

No adverse long-term effects on general health or reproductive performance were observed in any of the ewes that survived exposure to a single, nearlethal dose of 1080 . Throughout a 2-year period, including two lambing cycles, 1080-exposed and control ewes did not differ in mortality, and the indices of health and productivity such as general condition/live mass, haematology and serum clinical biochemistry parameters, incidence of infectious or metabolic disease, fleece mass, lambing percentage, lamb birth mass, lamb survival and lamb growth rate.

Histopathological examination of heart and brain from ewes killed at the termination of the study revealed scattered foci of fibrous tissue in cardiac muscle, which may represent scarring secondary to 1080-induced myocardial damage and small, focal lesions in several regions of the brain, indicative of chronic neuronal degeneration. These findings need to be interpreted with caution in view of the relatively small sample size. In addition, from a diagnostic perspective, these lesions are non-specific and could result from a variety of other toxic or non-toxic insults. Therefore, in light of the lack of apparent adverse effects on the general health and performance of these animals, the clinical significance of heart, brain and lung lesions is uncertain. Finding similar lesions in animals suspected of exposure to 1080 would strengthen the case for implicating 1080 as the causative agent, but their presence or absence could not be considered definitive proof.

Repeated exposure of rats to small doses of fluoroacetate appears to afford some protection to subsequent challenge (Egekeze \& Oehme 1979). This is not the case in sheep, probably because even small doses of fluoroacetate result in myocardial damage in this species and this damage can be cumulative on subsequent exposure (Annison et al. 1960). In sheep that received multiple sublethal doses of 1080 , myocardial degeneration and focal necrosis of individual or small groups of myocardial fibres have been reported (Schultz et al. 1982). Researchers in Australia (Whittem \& Murray 1963) reported microscopic lesions in the heart, described as acute, multifocal injury to the myocardium after 1080 doses as low as $0.11 \mathrm{mg} / \mathrm{kg} /$ day for $3-7$ days. A dose of $0.11 \mathrm{mg} / \mathrm{kg}$ is approximately equivalent to a $30 \mathrm{~kg}$ sheep eating half of one $4 \mathrm{~g}$ cereal bait pellet containing $0.15 \%$ $1080 \mathrm{w} / \mathrm{w}$. Mild cardiac histopathological changes occurred with doses as low as $0.055 \mathrm{mg} / \mathrm{kg} / \mathrm{day}$, but the duration of treatment was not specified (Whittem \& Murray 1963). Thus, although 1080 itself is metabolized and excreted relatively rapidly, and therefore does not accumulate in tissue (Rammell 1993; Eason et al. 1994), cumulative damage to the heart or other organs from repeated exposure to sublethal doses of the toxin may occur.

Histochemical examination of sheep brains for signs of chronic, 1080-induced neuronal damage was performed on only three animals at the termination of the study. Conclusions must therefore be regarded as preliminary. However, the pattern of damage seen was consistent, although minor in scope, and allows some inferences to be drawn.

The striatum and hippocampus are noted for their vulnerability to neural insults, particularly those associated with energy deprivation (Choi 1988; Olney 1990). Sodium monofluoroacetate has been associated with inhibition of glial cell uptake (Hassel et al. 
1997). This effect may lead to increased extracellular concentrations of glutamate, an excitatory amino acid neurotransmitter which in excess may cause excitotoxin-type damage to neurons (Nicoletti, Bruno, Copani, Casabona \& Knopfel 1996). The striatum, hippocampus and cerebellum are all susceptible to this type of damage. The effects of excess glutamate are exacerbated by the formation of nitric oxide, a highly reactive peroxide, dependent on NOS for its synthesis (Yamamoto 1992; Akira, Henry, Baldwin \& Wasterlain 1994; Bonofoco, Kranic, Ankarcrona, Nicotera \& Lipton 1995). All of the brain regions that showed signs of neuronal damage in this study were associated with the presence of NOS-containing neurons.

Interestingly, the nucleus tractus solitarius, an area that showed signs of neuronal degeneration in this study, is associated with cardio-respiratory control (Cohen 1981). It is tempting to speculate that 1080induced damage to this area may play a role in cardio-respiratory depression frequently associated with late stages of 1080 intoxication. The neural basis for clinical signs associated with 1080 intoxication was recently investigated (Cook, Eason, Wickstrom \& Devine 2000) as a basis for an antidote.

In conclusion, the results of this study suggest that a single exposure to 1080 , even at near-lethal doses, is unlikely to have significant long-term effects on the health or productivity of sheep. Substantial losses of sheep on some farms in New Zealand were on occasion linked to 1080 use in the early 1990s (Paul Livingstone, personal communication 1994). This study provides no evidence for such a linkage with deaths occurring more than 4 days following exposure. However, if sheep were allowed access to partially degraded baits over a period of days or weeks, ingesting multiple sublethal doses, the outcome might be different, particularly if they are subjected to climatic or other forms of stress together with 1080 exposure.

\section{ACKNOWLEDGEMENT}

We thank the Animal Health Board for its financial support of this research project.

\section{REFERENCES}

AKIRA, T., HENRY, D., BALDWIN, R.A. \& WASTERLAIN, C.G. 1994. Nitric oxide participates in excitotoxin mechanisms induced by chemical hypoxia. Brain Research, 645:285-290.

ANNISON, E.F., HILL, K.J., LINDSAY, D.B. \& PETERS, R.A. 1960. Fluoroacetate poisoning in sheep. Journal of Comparative Pathology, 70:145-155.
BOARD, P.G. \& PETER, D.W. 1976. A simple test for glutathione peroxidase and selenium deficiency. Veterinary Record, 99: 144.

BONOFOCO, E., KRANIC, D., ANKARCRONA, M., NICOTERA, P. \& LIPTON, S. 1995. Apoptosis and necrosis: two distinct events induced, respectively, by mild and intense insults with NMDA or nitric oxide/superoxides in cortical cell cultures. Proceedings of the National Academy of Sciences, USA, 92: 7162-7166.

BOWSAKOWSKI, T. \& LEVIN, A.A. 1986. Serum citrate as a peripheral indicator of fluorocitrate toxicity in rats and dogs. Toxicology and Applied Pharmacology, 85:428-436.

BUFFA, P., GUARRIERO-BOBYLEVA, V. \& COSTA-TLOZZO, R. 1973. Metabolic effect of fluoroacetate poisoning in animals. Fluoride, 6:224-227.

CHI, C.H., CHEN, K.W., CHAN, S.H., WU, M.H. \& HUANG, J.J. 1996. Clinical presentation and prognostic factors in sodium monofluoroacetate intoxication. Journal of Toxicology and Clinical Toxicology, 34:707-712.

CHOI, D.W. 1988. Glutamate neurotoxicity and diseases of the nervous system. Neuron, 1:623-634.

COHEN, M.I. 1981. Central determinants of respiratory rhythm. Annual Review of Physiology, 43:91-123.

COOK, C., EASON, C.T., WICKSTROM, M. \& DEVINE, C.D. 2000. Development of antidotes for sodium monofluoroacetate (1080). Biomarkers, 6:1-4.

EASON, C.T. 1997. Sodium monofluoroacetate toxicology in relation to its use in New Zealand. Australasian Journal of Ecotoxicology, 3:57-64.

EASON, C.T., GOONERATNE, R., FITZGERALD, H., WRIGHT, G. \& FRAMPTON, C. 1994. Persistence of sodium monofluoroacetate in livestock animals and risks to humans. Human and Experimental Toxicology, 13:119-122.

EASON, C.T., WICKSTROM, M., TURCK, P. \& WRIGHT, G.R.G. 1999. A review of recent regulatory and environmental toxicology studies on 1080: results and implications. New Zealand Journal of Ecology, 23:129-137.

EASON, C.T. \& TURCK, P.A. 2002. A 90-day toxicology evaluation of compound 1080 (sodium monofluoroacetate) in Sprague-Dawley rats. Toxicological Sciences, 69:439-447.

EGEKEZE, J.O. \& OEHME, F.W. 1979. Sodium monofluoroacetate (SMFA, Compound 1080): A literature review. Veterinary and Human Toxicology, 21:411-416.

GAI, W.P. \& BLESSING, W.W. 1996. Human brainstem preganglionic parasympathetic neurons localised by markers for nitric oxide synthesis. Brain Research, 119:1145-1152.

GARDNER, P.R., NGUYEN, D. \& WHITE, C.W. 1994. Aconitase is a sensitive and critical target of oxygen poisoning in cultured mammalian cells and in rat lungs. Proceedings of the National Academy of Science, 91:12248-12252.

GOONERATNE, R., EASON, C.T., DICKSON, C., FITZGERALD, H., WRIGHT, G. \& WALLACE, O. 1994. Persistence of 1080 in rabbits after lethal and sublethal doses. Proceedings of the Science Workshop on 1080. Royal Society of New Zealand Miscellaneous Series, 28:67-74.

HASSEL, B., BACHELARD, H., JONES, P., FONNUM, F. \& SONNEWALD, U. 1997. Trafficking of amino acids between neurons and glia in vivo. Effects of inhibition of glial metabolism in vivo by fluorocitrate. Journal of Cerebral Blood Flow and Metabolism, 17:1230-1238.

JONES, T.C., HUNT, R.D. \& KING, N.W. 1997. Diseases due to protozoa, in Veterinary Pathology, $6^{\text {th }}$ ed. Baltimore, USA: Williams and Wilkins. 
KOENIG, H. 1969. Acute axonal dystophy caused by fluorocitrate. The role of mitochondrial swelling. Science, 164:310312.

LEMAIRE, L., ARELLANO, M., MALET-MARTINO, M.C., MARTINO, R., DE FORNI, M. 1994. Cardiotoxicity of 5-fluorouracil: a question of formulations. Bulletin Cancer, 81:1057- 1059.

MATSUBARA, I., KAMIYA, J. \& IMAI, S. 1980. Cardiotoxic effects of 5-fluorouracil in the guinea pig. Japanese Journal of Pharmacology, 30:871-879.

MCDOWELL, E.M. 1972a. Light- and electron-microscopic studies of the rat kidney after administration of inhibitors of the citric acid cycle in vivo. Changes in the proximal convoluted tubule during fluorocitrate poisoning. Journal of Pathology, 108:303-318.

MCDOWELL, E.M. 1972b. Light- and electron-microscopic studies of the rat kidney after administration of inhibitors of the citric acid cycle in vivo. I. Effects of sodium monofluoroacetate on the proximal convoluted tubule. American Journal of Pathology, 66:513-530.

MEAD, R.J., MOULDEN, D.L. \& TWIGG, L.F. 1985. Significance of sulfhydryl compounds in the manifestation of fluoroacetate toxicity to the rat, brush-tail possum, woylie and western grey kangaroo. Australian Journal of Biological Sciences, 38:139149.

NICOLETTI, F., BRUNO, V., COPANI, A., CASABONA, G. \& KNOPFEL, T. 1996. Metabotropic glutamate receptors: a new target for the therapy of neurodegenerative disorders? Trends in Neuroscience, 19:267-271.

OLNEY, J. 1990. Excitotoxin mediated neuron death in young and old age. Progress in Brain Research, 86:37-49.

PETERS, R.A. 1963. Biochemical lesion and lethal synthesis. New York: Pergman Press.
RAMMELL, D. 1993. Persistence of compound 1080 in sheep muscle and liver. Surveillance, 20:20-21.

ROY, A., TAITELMAN, V. \& BURSTEIN, S. 1980. Evaluation of the role of ionized calcium in sodium fluoroacetate (1080) poisoning. Toxicology and Applied Pharmacology, 56:216220.

SCHULTZ, R., COETZER, J.A., KELLERMAN, T.S. \& NAUDE, T.W. 1982. Observations on the clinical, cardiac, and histopathological effects of fluoroacetate in sheep. Onderstepoort Journal of Veterinary Research, 49:237-245.

SCHUMED, L.C., ALBERTSON, C. \& SLIKKER, W. 1997. Fluoro-Jade: a novel fluorochrome for the sensitive and reliable histochemical localisation of neuronal degeneration. Brain Research, 751:37-46.

SMITH, F.A., GARDNER, D.E., YUILE, C.L., DE LOPEZ, O.H. \& HALL, L.L. 1977. Defluorination of fluoroacetate in the rat. Life Science, 20:1131-1138.

SULLIVAN, J.L., SMITH, F.A. \& GARMAN, R.H. 1979. Effects of fluoroacetate on the testis of the rat. Journal of Reproduction and Fertility, 56:201-207.

TWIGG, L.E., KING, D.R. \& BRADLEY, A.J. 1988. The effect of sodium monofluoroacetate on plasma testosterone concentration in Tiliqua rugosa (Gray). Comparative Biochemistry and Physiology, 91:343-347.

WHITTEM, J.H. \& MURRAY, L.R. 1963. The chemistry and pathology of Georgina river poison. Australian Veterinary Journal, 39:168-173.

YAMAMOTO, H. 1992. Protective effects of N-nitro-L-arginine against cyanide induced convulsions in mice. Toxicology, 71 : 277-283. 